Pontifícia Universidade $C_{\text {atólica }}$

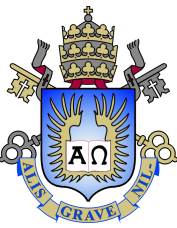

Guilherme Neves Silveira

\title{
Credit Crunches and Inequality Dynamics
}

\section{Dissertação de Mestrado}

Thesis presented to the Programa de Pós-graduação em Economia da PUC-Rio in partial fulfillment of the requirements for the degree of Mestre em Economia .

Advisor: Prof. Eduardo Zilberman 
Guilherme Neves Silveira

\section{Credit Crunches and Inequality Dynamics}

Thesis presented to the Programa de Pós-graduação em Economia da PUC-Rio in partial fulfillment of the requirements for the degree of Mestre em Economia. Approved by the undersigned Examination Committee.

Prof. Eduardo Zilberman

Advisor

Departamento de Economia - PUC-Rio

Prof. Carlos Viana de Carvalho Departamento de Economia - PUC-Rio

Prof. Pedro Cavalcanti Ferreira Escola Brasileira de Economia e Finanças - FGV/EPGE

Prof. Augusto Cesar Pinheiro da Silva

Vice Dean of Graduate Studies Centro Técnico Científico - PUC-Rio 
All rights reserved.

\section{Guilherme Neves Silveira}

B.A., Economics, Escola de Economia de Sao Paulo (FGV/EESP), 2015

Bibliographic data

Silveira, Guilherme Neves

Credit Crunches and Inequality Dynamics / Guilherme Neves Silveira; advisor: Eduardo Zilberman. - Rio de janeiro: PUC-Rio, Departamento de Economia , 2018.

v., 37 f: il. color. ; $30 \mathrm{~cm}$

Dissertação (mestrado) - Pontifícia Universidade Católica do Rio de Janeiro, Departamento de Economia .

Inclui bibliografia

1. Economia - Teses. 2. Desigualdade de riqueza;. 3. Empreendedorismo;. 4. Má-alocação;. I. Zilberman, Eduardo. II. Pontifícia Universidade Católica do Rio de Janeiro . Departamento de Economia . III. Título. 


\section{Acknowledgments}

I am extremely indebted to my family and friends, without which I would never make it this far. I would also like to thank Prof. Eduardo Zilberman, whose guidance was a constant company throughout the past two years. 


\section{Abstract}

Silveira, Guilherme Neves; Zilberman, Eduardo (Advisor). Credit Crunches and Inequality Dynamics. Rio de Janeiro, 2018. 37p. Dissertação de mestrado - Departamento de Economia , Pontifícia Universidade Católica do Rio de Janeiro .

I develop an entrepreneurship model with occupational choices in an environment where agents face binding credit restrictions. I show that in economies where financial markets are tighter, the distribution of wealth is characterized by higher levels of inequality. The model is consistent with documented results in the literature concerning losses in TFP and other aggregate outcomes. I also analyze the transition dynamics of the wealth distribution in the aftermath of a once-and-for-all credit crunch shock and show that wealth accumulation might mitigate the misallocation implied by such adverse shocks.

\section{Keywords}

Wealth inequality; Entrepreneurship; Misallocation; 


\section{Resumo}

Silveira, Guilherme Neves; Zilberman, Eduardo. Fricções Financeiras e Dinâmicas da Desigualdade. Rio de Janeiro, 2018. 37p. Dissertação de Mestrado - Departamento de Economia , Pontifícia Universidade Católica do Rio de Janeiro .

Eu desenvolvo um modelo de empreendedorismo com escolha ocupacional em que os agentes se deparam com restrições ao crédito. Eu mostro que em economias em que os mercados financeiros são mais apertados, a distribuição de riqueza é caracterizada por níveis mais elevados de desigualdade. O modelo é consistente com resultados documentados na literatura acerca de perdas de PTF e outros resultados agregados. Eu também analiso a dinâmica de transição da distribuição de riqueza depois de um choque permanente e negativo no crédito disponível às familias e mostro que a acumulação de riqueza pode mitigar a má-alocação decorrente de tais choques.

\section{Palavras-chave}

Desigualdade de riqueza; Empreendedorismo; Má-alocação; 


\section{Table of contents}

1 Introduction $\quad 10$

2 The Model $\quad 13$

2.1 Environment 13

2.2 Financial Frictions and Credit Crunches 14

$\begin{array}{lll}2.3 & \text { Steady-State Equilibrium } & 16\end{array}$

3 Calibration $\quad 17$

3.1 Wealth-Linear Restriction $(k \leq \lambda a) \quad 18$

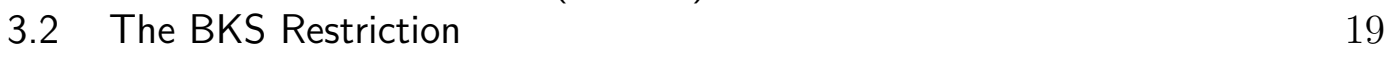

$4 \quad$ Steady-State Analysis $\quad 21$

4.1 Wealth-Linear Restriction $(k \leq \lambda a) \quad 21$

4.2 The BKS Restriction 24

5 Transition Dynamics $\quad 28$

5.1 Wealth-Linear Restriction 28

5.2 The BKS Restriction 31

6 Conclusions $\quad 34$

$\begin{array}{ll}\text { Bibliography } & 35\end{array}$

$\begin{array}{lll}\text { A Appendix } & 37\end{array}$ 


\section{List of figures}

Figure 4.1 Wealth Distribution 22

Figure 4.2 Wealth Distribution of Entrepreneurs 22

Figure 4.3 Binded x Slack Entrepreneurs 23

$\begin{array}{lll}\text { Figure 4.4 Wealth Distribution } & 25\end{array}$

Figure 4.5 Wealth Distribution of Entrepreneurs 25

Figure 4.6 Binded x Slack Entrepreneurs 26

Figure 4.7 Capital Restrictions (Most Productive Entrepreneur) 26

$\begin{array}{lll}\text { Figure 5.1 Capital and Interest Rate } & 29\end{array}$

Figure 5.2 Gini Coefficient and Wealth Distribution 30

Figure 5.3 Welfare Decomposition 31

Figure 5.4 Capital and Interest Rate 31

Figure 5.5 Gini Coefficient and Wealth Distribution 32

Figure 5.6 Welfare Analysis 33 


\section{List of tables}

$\begin{array}{lll}\text { Table 3.1 } & \text { External Calibration } & 18\end{array}$

Table 3.2 Target Moments and Model Fit 18

Table 3.3 Internal Calibration 19

Table 3.4 Target Moments and Model Fit 20

$\begin{array}{lll}\text { Table } 3.5 & \text { Internal calibration } & 20\end{array}$

Table 4.1 Model Predicted Moments 24

$\begin{array}{lll}\text { Table } 4.2 \text { Model Predicted Moments } & 27\end{array}$

Table 5.1 Quantitative Comparison 33 


\section{Introduction}

Since the onset of the global financial crisis, financial frictions have been given growing importance in the modeling of DSGE models, and, at the same time, dug a place up in the economic debate around the globe. In its 2012's Report To Congress, the Federal Reserve documented a sharp decrease in bank loans to small businesses, which plummeted from US\$ 616.1 in 2008 to US\$ 529.7 in 2011 (in millions of dollars). In such a scenario, self-financing and collateral loans might have a bigger role for entrepreneurial activity and for entrepreneurs to be. In fact, in the 2007's US Census's Survey of Small Business Owners, 62 percent of the surveyed managers reported that they had to rely on their own personal savings to start their businesses. In the 2012's Survey, this number was even higher, amounting to roughly 67 percent of the respondents.

The main purpose of this work is to investigate how such a widespread financial deleveraging affects the wealth distribution of households when selffinancing is a relevant source of credit resources. In particular, I study the implications of a credit crunch shock to the economy's wealth inequality along the transition to a new steady-state. In order to do so, I model an economy where agents are heterogeneous in their ability to manage a firm and in their asset holdings and choose at every instant whether to run a business or to work for one. Capital markets are imperfect, in the sense that potential entrepreneurs are limited to a multiple of their personal wealth in order to invest in capital. I also model a financial constraint in which the maximum amount entrepreneurs can borrow is not only linked to their wealth, but also to their managerial talent.

In the presence of capital restrictions, both an agent's accumulated wealth and her managerial skill are relevant for the decision to become an entrepreneur. This occupational choice effect relates to the extensive margin of the entrepreneurial activity. In the absence of financial frictions, the managerial productivity would be the only determinant of an agent's occupation. Furthermore, since active entrepreneurs face collateral constraints linked to their asset position, wealthy entrepreneurs are more prone to invest the efficient amount of capital in their plants, whilst entrepreneurs with low levels of wealth are more likely to invest less than they would otherwise. This 
relates to the intensive margin of the entrepreneurial activity. In this sense, wealth accumulation is a relevant mechanism through which agents can not only mitigate misallocation in occupations, but also promote a level of capital investment closer to the efficient one. In a scenario in which entrepreneurs are suddenly presented to a negative credit shock, this mechanism may become more salient and thus influence the wealth inequality path following such a shock.

The bulk of the related literature leans on entrepreneurship models with financial frictions to investigate differences in total factor productivity (TFP) and GDP levels across countries. It is often argued that in the developing world, imperfect credit markets dampens the business activity and promote pervasive miscallocation. In a model calibrated for the Brazilian economy, (1) investigate the effects of eliminating financial frictions on aggregate productivity and show that in the absence of those, gains in TFP range from $9 \%$ to $27.3 \%$. In a related model, enriched with taxation and bequests, (2) were able to fit very well some statistics describing wealth characteristics of entrepreneurs in the American economy and quantified the impact of different negative credit shocks to some activity outcomes regarding the economy as a whole as well as some firmlevel attributes (e.g. firm size, measured as the number of employees, earnings, etc.). They found out that the extent to which entrepreneurial wealth is eroded was tantamount to determining the speed of the economy's recovery in the aftermath of an adverse financial shock.

(3) was the first paper that excelled in matching the high levels of wealth inequality observed in the United States data, stressing the importance of including entrepreneurship modelling in the heterogeneous agents literature in order to achieve this goal. The author was aiming to explain the different patterns in wealth mobility between workers and entrepreneurs. His model was able to frame the empirical evidence that business owners increase their wealth concentration throughout their lives, whilst workers wealth concentration is downward sloping. (4) was able to enrich (3)'s model and fit important moments of the entire wealth distribution of the American economy in 2006. The authors goal was to investigate to which extent financial frictions explain the observed wealth inequality. Through a comparative statics exercise, the authors show that more stringent financial restrictions are associated with lower levels of wealth inequality in the steady-state equilibrium.

My main contribution is to provide the literature of entrepreneurship models in the presence of financial frictions with the transition dynamics implied by a credit crunch shock, replicating the drastic fall in outstanding credit to the private sector in the American economy observed in the Global 
Financial Crisis of 2008. To the best of my knowledge, the related literature had only focused on the steady-state implications of imperfect credit markets. My work leverages itself on the recent developments in heterogeneous agents models in continuous time (HACT), being mainly advanced by (5). The method relies on solving a system of partial differential equations, being not only computationally efficient but also numerically precise, abdicating simulationbased methods largely adopted in the solution of this class of models.

The main finding of the present work is that a capital restriction that solely depends on wealth generates weak effects on the entrepreneurial activity of the model economy when compared to a financial friction that reflects both an agent's wealth and productivity. Wealth inequality in both specifications are predicted to rise in the aftermath of a credit crunch shock, although again, when the credit market imperfection is modeled as function of both wealth and managerial talent, wealth inequality increases more sharply (787 basis points against $433 \mathrm{bps}$ ). When it comes to welfare losses, again, in a setting where capital investments are exclusively collaterized by the entrepreneurs accumulated wealth, a credit crunch shock predicts a reduction in aggregate welfare of only $0.3 \%$, meanwhile in the other modeled restriction, the welfare losses amount to $10 \%$.

This work unfolds as follows. In Section 2, the model is presented. In Section 3, the calibration strategy is properly described. In Section 4, I provide some comparative statics exercises involving the steady-state equilibrium outcomes of the model economy encompassing both a tighter and a looser credit market setting. Finally, in Section 5, I provide the transition dynamics implied by a credit crunch shock. 


\section{2}

\section{The Model}

\section{1}

\section{Environment}

Time is continuous. There is a unit mass of infinitely lived agents, each of them indexed by their productivity factor $z$ and their accumulated wealth $a$. Productivity $z$ is generated by a stochastic process and it is observable. At every instant $t$, the state of the economy may be understood as the mass of agents located in each possible combination of wealth $a$ and productivity $z$. Let $g(a, z, t)$ represent it. Individuals discount future payoffs at the rate $\rho$ and face an exogenous probability of dying, $\eta$. Preferences are given by

$$
E_{0} \int_{0}^{\infty} e^{-(\rho+\eta) t} u\left(c_{t}\right) d t
$$

Every agent is a potential entrepreneur in the economy, in the sense that, at every instant, they choose whether to run a business or to work for one. Productivity $z$ determines the stochastic nature of the production function of active entrepreneurs, and it may be interpreted as an agent's managerial talent. ${ }^{1}$ Only after observing their productivity $z$, agents make the pertinent occupational choice and since productivity is drawn at every instant, an agent's occupation may vary from one period to another.

In the model economy, entrepreneurs act as the owners of the business plant, hiring labor $l$ and capital $k$ in order to produce $f(k, l ; z)$ units of output, with $f(k, l ; 0)=0$. Capital markets are imperfect. Every entrepreneur faces collateral constraints of the form

$$
k \leq \bar{k}(a, z ; \lambda)
$$

where $\lambda$ captures the availability of outstanding credit in the economy. For now, an explicit formulation of $\bar{k}(a, z ; \lambda)$ is deemed unimportant.

Define the profit function as

$$
\pi(a, z)=\max _{k, l} f(k, l ; z)-(r+\delta) k-w l-\kappa \quad \text { s.t. } \quad k \leq \bar{k}(a, z ; \lambda),
$$

${ }^{1} \mathrm{I}$ abstract from uncertainty in labor productivity, i.e., if an agent decides to be a worker, her labor income will be, with certainty, the wage at which she is hired. See (4) and (1) for models in which labor productivity is stochastic. 
in which $w$ and $r$, the economy prices, respectively represent the wage at which labor is hired and the risk-free interest rate at which capital is rented and wealth is accrued; $\delta$ and $\kappa$ are the depreciation rate of capital and a fixed cost of operating the firm, respectively. Then, the wealth accumulation process may be written as

$$
\dot{a}=\max \{\pi(a, z), w\}+r a-c=s(a, z, c) .
$$

Therefore, savings are represented by the income and wealth proceedings net of consumption expenditures. In this formulation, precautionary savings are more salient for active entrepreneurs, since their consumption streams are state-dependent, i.e. realized profits inherit the uncertainty coming from the productivity process, whereas workers have a deterministic income.

The consumer's optimization problem boils down to maximizing the present discounted value (PDV) of utility flows in (2-1) subject to the budget constraint in (2-4). The associated Hamilton-Jacobi-Bellman (HJB) equation ${ }^{2}$ is given by

$$
(\rho+\eta) v(a, z)=\max _{c} u(c)+E\left[\frac{d v(a, z)}{d t}\right]
$$

\section{2}

\section{Financial Frictions and Credit Crunches}

The financial friction in the baseline model is specified as a limit on the amount of credit entrepreneurs can borrow to invest in capital. Although not explicitly defined, the limit $\bar{k}(a, z ; \lambda)$ was let to vary according to the entrepreneur's wealth $a$, productivity $z$, and, finally, on the parameter $\lambda$ that captures the availability of credit in the economy.

Below I present two different specifications for the credit restriction. The first capital constraint is based on (7), from now on referred as the BKS restriction. They motivate the adoption of this restriction as an economy where banks (lenders) cannot fully enforce the payment of credit issued to entrepreneurs (borrowers). In other words, after a default, banks can only retrieve a fraction of the entrepreneurs' profits and wealth. The only available credit contract for the banks is a quantity contract, which may be understood as a limit on the amount of credit they can lend to entrepreneurs. For each type of entrepreneur, i.e. her wealth $a$ and productivity $z$, banks choose the maximum amount of credit they can lend and they do so by guaranteeing that the borrower is (weakly) better off with fulfilling their obligations than defaulting on them ${ }^{3}$.

\footnotetext{
${ }^{2}$ See the appendix.

${ }^{3}$ Naturally, the underlying assumption is that an agent's wealth and productivity are both observable to banks.
} 
Although modeling financial frictions of this kind has a sound reasoning, it is another feature of it that might be particularly appealing. The authors show that the optimal quantity contract is weakly increasing in both wealth and productivity, i.e., richer and more productive entrepreneurs have a higher amount of credit available to invest in capital and, consequently, face restrictions less likely to bind. This feature is not present in restrictions that are solely wealth dependent ${ }^{4}$. In this formulation, which will be the second one adopted here, the accumulation of wealth has more clear consequences on the extensive and intensive margins of the entrepreneurial activity: the amount of accumulated wealth is decisive for an agent to open a firm (the extensive margin); active entrepreneurs are more likely to employ the desired amount of capital the richer they are (the intensive margin).

However, in both scenarios, i.e. the BKS restriction and the wealth-only restriction, imperfect credit markets may lead to not obvious consequences regarding the distribution of wealth among individuals. Since more productive managers have a higher demand for capital, they are prone to face more binding credit restrictions. This could impose an upper-bound on profits and, the more imperfect the credit market, the smaller it is this upper-bound. By trimming the right tail of the profits' distribution, it dampens the accumulation of wealth for the richest and most talented agents, and it could be the case that a credit crunch shock may, in fact, reduce wealth inequality, as it is the case in (4).

\section{Definição 2.1 The BKS Specification}

The limit on the amount of credit $\bar{k}$ to be lent to entrepreneurs is given by the fixed point of the following equation:

$\max _{l}\{f(l, \bar{k} ; z)-w l\}-(r+\delta) \bar{k}+(1+r) a-\kappa=(1-\lambda)\left[\max _{l}\{f(l, \bar{k} ; z)-w l\}+(1-\delta) \bar{k}\right]$

The left-hand side (LHS) of the equation is profits and wealth proceedings net of the payment of capital obligations and the fixed cost of operation, whilst the right-hand side (RHS) represents the income proceedings that an entrepreneur would have left after the creditor had seized a fraction $\lambda$ of it, in case of default. An optimal enforceable contract, $\bar{k}$, should guarantee that the LHS is at least as big as the RHS. For almost every combination of wealth $a$ and productivity $z$, there is a fixed point $\bar{k}>0$ that solves (2-6), making entrepreneurs indifferent between abiding to their obligations and defaulting on them. For the pairs of

${ }^{4}(8),(9)$ and (10), just to cite some, use a restriction that is linear in wealth and does not depend on the productivity factor. 
$a$ and $z$ that there is no positive level of capital that solves the equality, $\bar{k}$ is set to zero.

In the models where this kind of credit restriction is usually employed, $\lambda$ represents the fraction of the entrepreneur's profit that the banking sector would be able to recover after a default. However, this parameter implicitly defines the amount of available credit to the firms relative to its manager's wealth. In this sense, one might emulate an unanticipated credit crunch, i.e. a sudden fall in the outstanding credit for the private sector, by changing the value of $\lambda$, and more specifically, by reducing it. ${ }^{5}$

The other specification for the capital restriction may be written as $k \leq \lambda a$, a simple restriction where $\lambda$ directly captures the degree of leverage in the economy. In this case, a reduction in $\lambda$ may be interpreted as a credit crunch shock.

\section{3}

\section{Steady-State Equilibrium}

A steady-state equilibrium in the modeled environment is composed by an interest rate $r$ and a wage $w$ such that capital and labor markets clear, and consumption/savings policy functions such that the PDV of utility flows is maximized. In such an equilibrium, the distribution of agents along the wealth and productivity space should also remain constant.

Definição 2.2 Steady-State Equilibrium

Let $k(a, z)$ and $l(a, z)$ denote the optimal capital and labor demand schedules for active entrepreneurs. Let also $1\{w \geq \pi(a, z)\}$ be 1 , if the agent indexed by her wealth $a$ and productivity $z$ is a worker, and 0 otherwise. A steady-state equilibrium consists of a pair of interest rate and wage $(r, w)$ such that capital (i) and labor markets (ii) clear; consumption/savings policy functions such that every agent maximizes (1) subject to (2-4); a steady-state distribution function $g(a, z)$ over the wealth and productivity space (iii).

$$
\begin{gathered}
\int_{a} \int_{z} k(a, z) g(a, z) d z d a=\int_{a} \int_{z} a g(a, z) \quad(i) \\
\int_{a} \int_{z} l(a, z) g(a, z) d z d a=\int_{a} \int_{z} 1\{w \geq \pi(a, z)\} g(a, z) \\
g(a, z, t)=g(a, z) \forall t \quad(i i i)
\end{gathered}
$$

\footnotetext{
${ }^{5}$ It is not obvious that, in equilibrium, a reduced value of $\lambda$ implies a reduced maximum quantity contract for every agent in the economy. Through total derivatives, one might show that it is possible that for some combinations of wealth $a$ and productivity $z$, the credit contracts are more generous with lower values of $\lambda$. Of course, it is a partial equilibrium result (i.e. wages and interest rates are fixed).
} 


\section{Calibration}

Three sets of parameters are calibrated. The first set involves agents preferences, the second, the production function of active entrepreneurs and the third one relates to the stochastic process for the productivity factor $z$. The calibration strategy unfolds in two stages: the first stage is an external calibration, in which a subset of the parameters is borrowed from the related literature; the second stage involves an internal calibration, in which the remaining parameters are chosen to minimize the distance between model generated statistics and empirical data. The second stage is done independently for both credit restriction specifications.

The instantaneous utility flow is given by

$$
u(c)=\frac{c^{1-\sigma}}{1-\sigma} .
$$

The production function features a decreasing returns to scale technology with respect to labor $l$ and capital $k$. This feature, alongside with the death probability $\eta$, guarantees the existence of a steady-state distribution over the wealth and productivity space, $g(a, z){ }^{1}$ The production function is given by

$$
f(k, l ; z)=z^{\alpha} k^{\beta} l^{\gamma}, \quad \gamma=1-\alpha-\beta .
$$

The stochastic process of the productivity factor $z$ is the continuous time analogue of an $\mathrm{AR}(1)$, usually adopted in the related literature to specify the labor income uncertainty. Productivity follows an Ornstein-Uhlenbeck process of the kind

$$
d \log (z)=-\theta \log (z) d t+\sigma d W,
$$

where $d W$ follows a Martingale Process. It is possible to show that $e^{-\theta}$ represents the autocorrelation of log-productivity and $\frac{\sigma^{2}}{2 \theta}$ its asymptotic variance. Implicit in (3-3), the asymptotic expectancy of $z$ is 1 .

${ }^{1}(10)$ was able to recover the steady-state distribution of wealth shares over the productivity space, i.e. for each agent indexed by productivity $z$, it was possible to recover the amount of wealth concentrated by her, relative to the economy's aggregate wealth. 


\begin{tabular}{lccc} 
Parameter & Description & Value & Source \\
\hline$\sigma$ & CRRA & 1.5 & Standard \\
$\alpha$ & Cobb-Douglas & 0.198 & $(1)$ \\
$\beta$ & Cobb-Douglas & 0.325 & $(1)$ \\
$\gamma$ & Cobb-Douglas & $1-\alpha-\beta$ & $(1)$ \\
$\delta$ & Annual Depreciation Rate of Capital & $6 \%$ & Standard
\end{tabular}

Table 3.1: External Calibration

In Table (3.1), there is a description of the set of parameters with values borrowed from related studies. All the parameter values are defined in an annual basis. In the subsequent sections, the second stage of the calibration process is done for each financial friction specification, holding fixed the first stage chosen values.

\section{1}

Wealth-Linear Restriction $(k \leq \lambda a)$

In the second stage, the remaining parameters are chosen in order to minimize the distance between some empirical statistics and its model analogues. Both data and model moments are depicted in Table (3.2). The target moments are borrowed from (4), where one may find the complete description of the dataset and a proper definition of entrepreneurship. ${ }^{2}$ The model aims to best represent the American economy in the year of 2006, when credit to the private sector reached its peak, and the external finance to GDP ratio was close to 3.2 , the chosen value for $\lambda .^{3}$

\begin{tabular}{lcc}
\multicolumn{1}{c}{ Moment } & Data & Model \\
\hline Gini Coefficient (Wealth) & 0.80 & 0.80 \\
Top 1 Wealth Share & 0.30 & 0.16 \\
Top 5 Wealth Share & 0.54 & 0.46 \\
Share of Entrepreneurs & $7.55 \%$ & $10.58 \%$ \\
Capital to Output Ratio & 3.0 & 3.0
\end{tabular}

Table 3.2: Target Moments and Model Fit

The parameters $\rho$ (instantaneous discount rate) and $\eta$ (the death rate) are directly linked to the wealth accumulation incentives for agents. The higher

\footnotetext{
${ }^{2}$ See (11) for a broad discussion on the most commonly adopted definitions for an entrepreneurship activity.

${ }^{3}$ I refer to (10) for a discussion on how to measure this index and also to the source, Finance Structure Database.
} 
their sum, the lesser the value of future consumption streams. Thus, $\rho$ and $\eta$ will discipline the capital (savings) to output ratio and the Gini Coefficient of Wealth, respectively. The persistence and volatility of the productivity factor $z$ also shape the wealth inequality in the model economy. The higher the persistence of productivity spells, the more time an agent spends at a given occupation, fostering discrepancies in savings behavior between workers and entrepreneurs. ${ }^{4}$ The persistence related parameter $\theta$ and the parameter $\sigma$ associated with the asymptotic variance of the productivity spells will target top 1 and top 5 wealth shares, i.e. the share of wealth held by the $1 \%$ and $5 \%$ richest agents relative to the overall economy wealth. Finally, the fixed cost of running a business $\kappa$ disciplines the share of entrepreneurs in the economy. However, it is noteworthy to stress that parameters and moments are all interrelated.

\begin{tabular}{lccc} 
Parameter & Description & Value & Target \\
\hline$\rho$ & Discount Rate & 0.03 & Capital to Output Ratio \\
$\eta$ & Death Rate & 0.01 & Wealth's Gini Coefficient \\
$\kappa$ & Fixed Cost of Operation & 0.94 & Share of Entrepreneurs \\
$\theta$ & Mean Reversion of $z$ & 0.01 & Top 1 Wealth Share \\
$\sigma$ & Volatility of $z$ & 0.06 & Top 5 Wealth Share
\end{tabular}

Table 3.3: Internal Calibration

Notes: The values for $\theta$ and $\sigma$ imply an autocorrelation of 0.99 and an asymptotic variance of 0.24 for log-productivity.

\section{2}

\section{The BKS Restriction}

In this section, I perform the second stage (internal) calibration for the model in which the financial friction is represented by the one formulated in (7). In opposition to the wealth-linear restriction, in this case $\bar{k}(a, z ; \lambda)$ is determined in equilibrium. Therefore, the set of internally calibrated parameters includes an additional component, $\lambda$, as well as another targeted moment, the external-finance to GDP ratio. For comparability, the new targeted moment value is 3.2 , the value associated to $\lambda$ in the previous section. Tables (3.4) and (3.5) display the model fit and the parameter values and description, respectively.

${ }^{4}$ See (6) for a more complete discussion. 


\begin{tabular}{lcc}
\multicolumn{1}{c}{ Moment } & Data & Model \\
\hline Gini Coefficient (Wealth) & 0.80 & 0.77 \\
Top 1 Wealth Share & 0.30 & 0.13 \\
Top 5 Wealth Share & 0.54 & 0.41 \\
Share of Entrepreneurs & $7.55 \%$ & $7.95 \%$ \\
Capital to Output Ratio & 3.0 & 3.0 \\
Ext. Finance to GDP Ratio & 3.2 & 3.2 \\
\multicolumn{3}{c}{ Table 3.4: Target Moments and Model Fit }
\end{tabular}

\begin{tabular}{lccc} 
Parameter & Description & Value & Target \\
\hline$\lambda$ & Credit Restriction & 0.69 & External Finance to GDP Ratio \\
$\rho$ & Discount Rate & 0.04 & Capital to Output Ratio \\
$\eta$ & Death Rate & 0.02 & Wealth's Gini Coefficient \\
$\kappa$ & Fixed Cost of Operation & 1.50 & Share of Entrepreneurs \\
$\theta$ & Mean Reversion of $z$ & 0.16 & Top 1 Wealth Share \\
$\sigma$ & Volatility of $z$ & 0.44 & Top 5 Wealth Share
\end{tabular}

Table 3.5: Internal calibration

Notes: The values for $\theta$ and $\sigma$ imply an autocorrelation of 0.85 and an asymptotic variance of 0.60 for log-productivity. 


\section{4}

\section{Steady-State Analysis}

In this section, I provide a comparative statics exercise involving the credit restriction for the American economy prior to the Global Financial Crisis of 2008 and the credit scenario in its aftermath. I will discuss the model predictions, in steady-state equilibrium, of an economy in which external finance to GDP ratio varies from 3.2 to 2.6, the level observed in 2010 for the United States. The exercise is done separately for each credit constraint specification.

\section{1}

\section{Wealth-Linear Restriction $(k \leq \lambda a)$}

For the wealth-linear restriction, the parameter $\lambda$ directly captures the credit availability for the American economy. Hence, its calibration is straightforward, so I will display the equilibrium outcomes for $\lambda=3.2$ and $\lambda=2.6$.

Figure (4.1) plots the steady-state cumulative distribution function of wealth implied by the model for both values of $\lambda$. In the pre-crisis economy $(\lambda=3.2)$, the share of agents with zero wealth is around $39.53 \%$. When $\lambda=2.6$, this value increases to $50.7 \%$. There is also a shift in the wealth percentiles beginning in the 85th, a threshold below which wealth percentiles are higher for $\lambda=3.2$. Above it, the relationship inverts. 


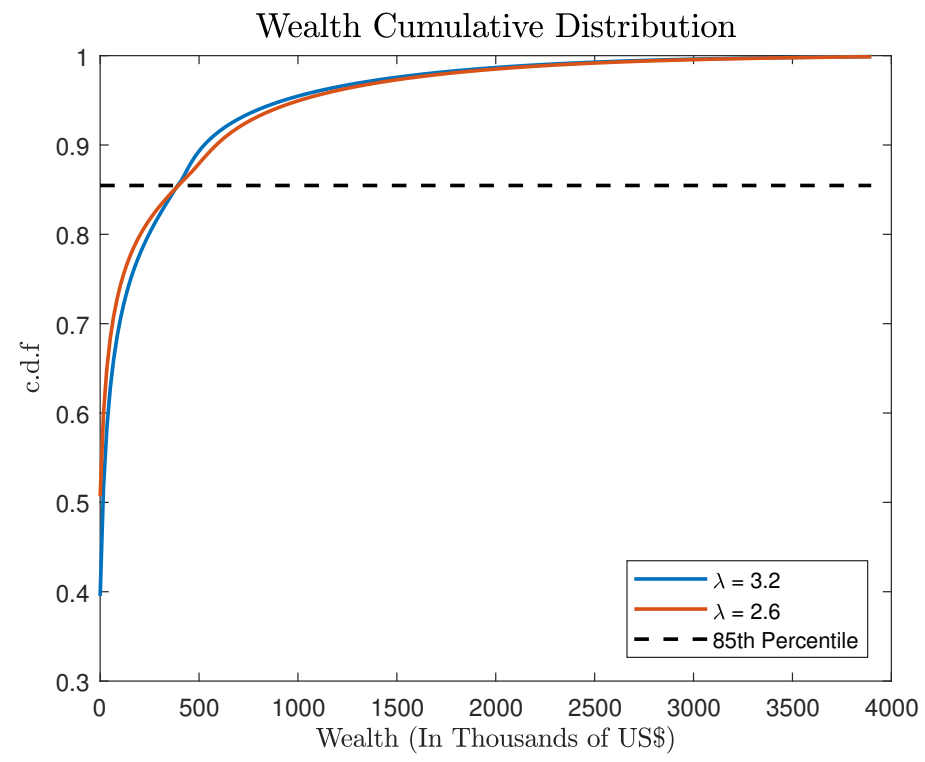

Figure 4.1: Wealth Distribution

When it comes to the savings behavior by occupation (see Figure 4.2), the model predicts a more salient change in the wealth distribution of entrepreneurs. Since workers face no uncertainty regarding labor income, the precautionary savings motive is completely shutdown. However, active entrepreneurs are more willing to save, specially in more stringent credit markets. A fall in the leverage ratio $\lambda$ puts a higher value in wealth accumulation, which might be perceived by the right-shift in the wealth distribution of active entrepreneurs.

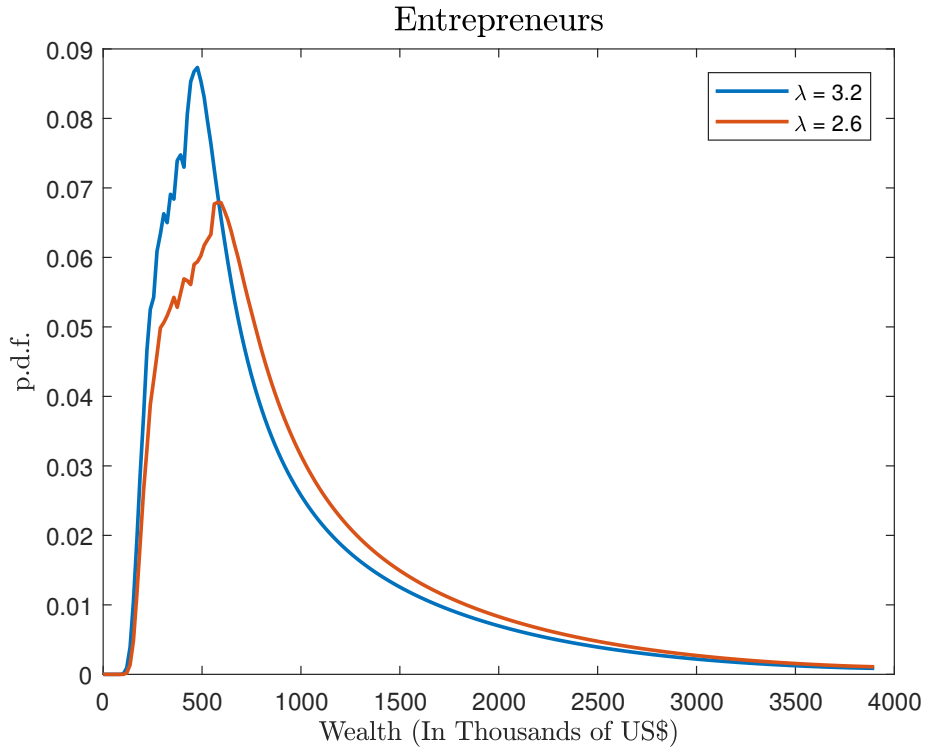

Figure 4.2: Wealth Distribution of Entrepreneurs 
Regarding the entrepreneurial activity, a lower value for $\lambda$ may have some implications for both the extensive margin of entrepreneurship, i.e. the decision to run a business, and the intensive margin, i.e. the amount of capital invested by entrepreneurs. The share of entrepreneurs in the model economy with $\lambda=2.6$ is $10.52 \%$, slightly smaller than the $10.58 \%$ of the economy where $\lambda=3.2$, meanwhile the share of binded entrepreneurs is $4.56 \%$ higher. Capital investments in the economy indexed by $\lambda=2.6$ is only $1 \%$ smaller. These small effects in the entrepreneurial activity may be explained by the increase in savings, propelling the wealth accumulation as a mechanism through which agents mitigate the misallocation effect of a more constrained credit market, as it is shown in Figure (4.3).
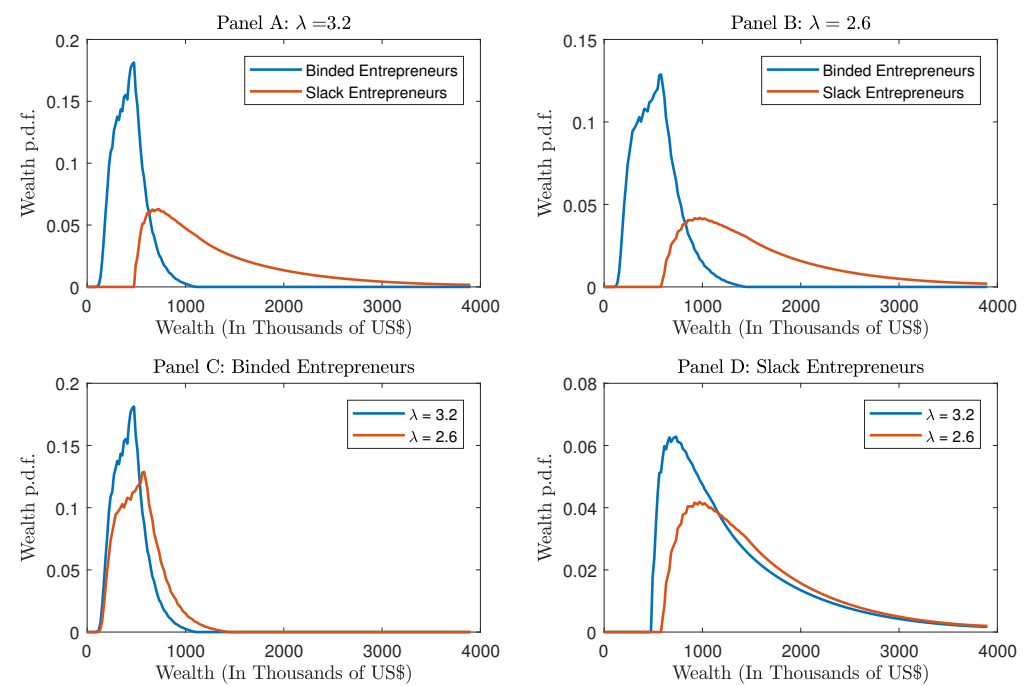

Figure 4.3: Binded x Slack Entrepreneurs

Finally, Table (4.1) describes the changes in the model statistics for both values of $\lambda$. In the post-crisis economy, wealth inequality is higher than in the pre-crisis calibrated model economy. The increase in the Gini Coefficient is led by the workers' wealth inequality. As it was aforementioned, the rise in inequality is captured by the bigger share of workers with zero wealth in the economy in which $\lambda=2.6$ vis-à-vis the economy indexed by $\lambda=3.2$. As it was previously mentioned, the share of entrepreneurs and the capital to output ratio are almost invariant to changes in the degree of financial frictions. 


\begin{tabular}{lcc} 
& $\lambda=3.2$ & $\lambda=2.6$ \\
\cline { 2 - 3 } Gini Coefficient (Wealth) & 0.80 & 0.84 \\
Gini Coeff. for Workers & 0.81 & 0.85 \\
Gini Coeff. for Entrepreneurs & 0.39 & 0.38 \\
Top 1 Wealth Share & 0.16 & 0.17 \\
Top 5 Wealth Share & 0.46 & 0.49 \\
Share of Entrepreneurs & $10.58 \%$ & $10.52 \%$ \\
Capital to Output Ratio & 3.00 & 2.97 \\
TFP & 0.20 & 0.19
\end{tabular}

Table 4.1: Model Predicted Moments

\section{2}

\section{The BKS Restriction}

As it was done in the previous section, I calibrate the parameter $\lambda$ in order to capture the availability of outstanding credit in the American economy prior to and after the Global Financial Crisis. The pre-crisis value of $\lambda$ is 0.69 , linked to an external finance to GDP ratio of 3.2. The value of $\lambda$ that generates a credit ratio of 2.6 is 0.63 .

The main difference between the wealth-linear capital restriction and the one presented here is that the latter is sensitive not only to an entrepreneur's wealth positions, but also to her productivity. Since more productive entrepreneurs have a higher demand schedule for both capital and labor, a restriction that only encompasses wealth as a collateral is more likely to trim the distribution of profits for the most productive agents, having a stronger (negative) effect in the resulting entrepreneurs wealth inequality. As it was shown in the previous section, in fact, entrepreneurs in a tighter credit market are more equally distributed in the wealth dimension, although not by a significant margin.

The c.d.f. of wealth implied by the endogenous credit market restriction is plotted in Figure (4.4). As it was the case in the wealth-linear restriction, the share of agents with zero-wealth is higher the tighter the capital constraint. When $\lambda=0.69$, the share is $46.7 \%$, while in the economy indexed by $\lambda=0.63$, this number reaches $58.28 \%$. The c.d.f.s intersect at the 92 th-percentile, above which wealth is more concentrated for the more stringent capital market economy. As it was the case in the previous credit imperfection, a tighter capital market propels entrepreneurs to save more, as it is shown in Figure (4.5). 


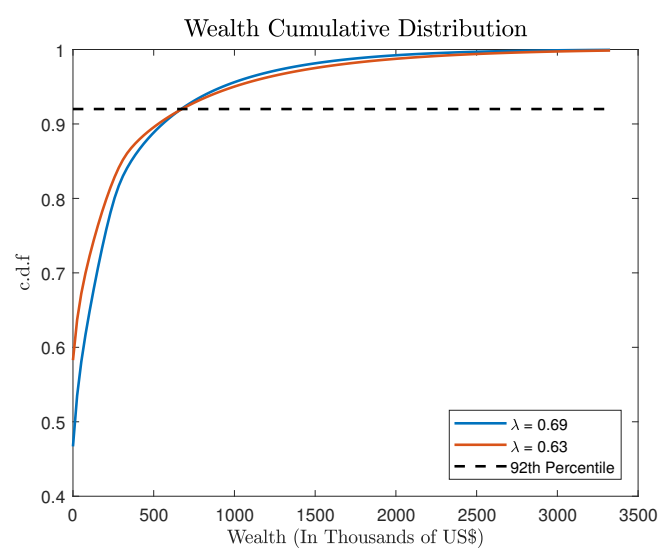

Figure 4.4: Wealth Distribution

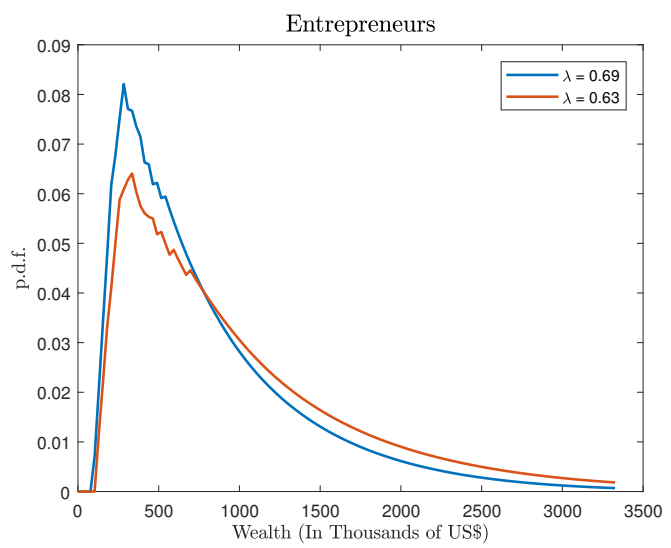

Figure 4.5: Wealth Distribution of Entrepreneurs

In Figure (4.6), Panels A and B, it is plotted the entrepreneurs' wealth distribution implied by both credit restriction parameters, $\lambda=0.69$ and $\lambda=0.63$, respectively. Independently of how tight the credit market is, in equilibrium the wealthiest entrepreneurs are the ones whose capital demand schedule is the efficient one (slack entrepreneurs). This result is robust to the financial friction specification, since it is also the case when the financial friction is linear in wealth. Panels $\mathrm{C}$ and $\mathrm{D}$ compares the change in the distribution of binded and slack entrepreneurs, separately. As it was documented for the wealth-linear restriction, there is a right shift in the wealth distribution of entrepreneurs, but it is more subtle in the BKS specification, specially for slack entrepreneurs. In fact, Figure (4.7) compares the capital restriction faced by the most productive entrepreneur. The BKS restriction is almost everywhere less tight than the wealth-linear restriction, which might promote a higher wealth accumulation for entrepreneurs in the model where the latter is included. 

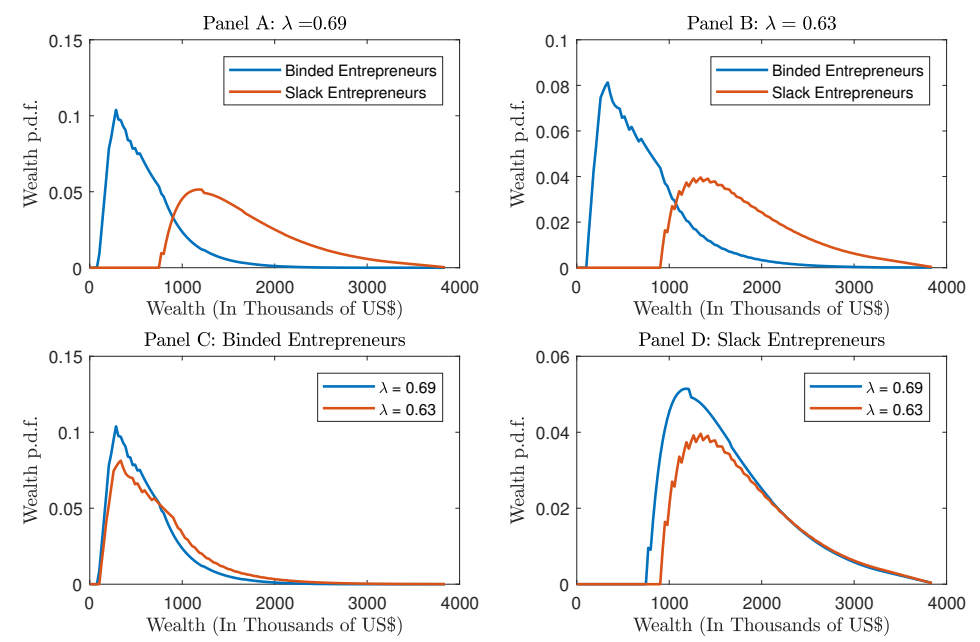

Figure 4.6: Binded x Slack Entrepreneurs

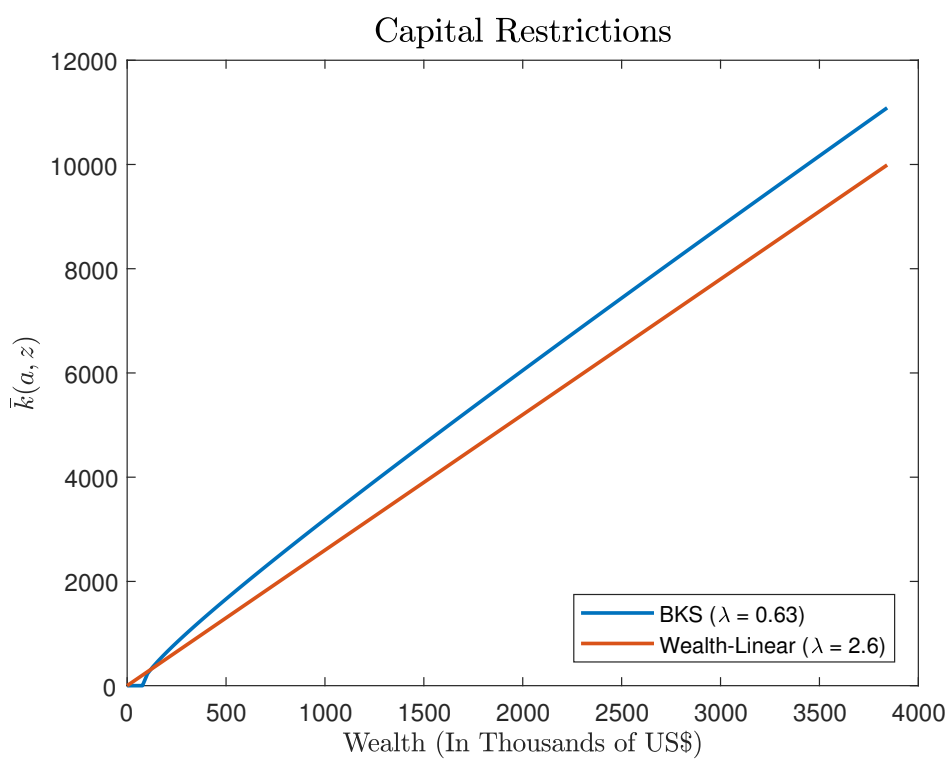

Figure 4.7: Capital Restrictions (Most Productive Entrepreneur)

When it comes to the extensive and intensive margins' effects of a more constrained capital market, the BKS restriction is responsible for a stronger effect on the entrepreneurial activity than its cohort. In the extensive margin, the share of entrepreneurs falls from $7.95 \%$ to $7.40 \%$. The amount of capital invested in the $\lambda=0.63$ economy is $6.46 \%$ smaller than in the $\lambda=0.69$ economy. Wealth inequality is also exacerbated, as it is described in Table (4.2), alongside to other model generated statistics. 


\begin{tabular}{lcc} 
& $\lambda=0.69$ & $\lambda=0.63$ \\
\cline { 2 - 3 } Gini Coefficient (Wealth) & 0.77 & 0.83 \\
Gini Coeff. for Workers & 0.78 & 0.85 \\
Gini Coeff. for Entrepreneurs & 0.38 & 0.39 \\
Top 1 Wealth Share & 0.13 & 0.16 \\
Top 5 Wealth Share & 0.41 & 0.49 \\
Share of Entrepreneurs & $7.95 \%$ & $7.40 \%$ \\
Capital to Output Ratio & 3.00 & 2.96 \\
TFP & 0.22 & 0.18 \\
External Fin. To GDP Ratio & 3.20 & 2.60
\end{tabular}

Table 4.2: Model Predicted Moments 


\section{5}

\section{Transition Dynamics}

In this section, I capture the dynamics of wealth accumulation and optimal individual behavior after a sudden, unanticipated credit crunch shock. The parameter calibration was kept unchanged to the ones used in the steadystate's outcomes evaluation. As it was previously done, this exercises is performed independently for both credit restrictions.

It is worthwhile to stress that in heterogeneous agents models in continuous time, optimal decisions are framed by a system of two partial differential equations given by a backward-looking Hamilton-Jacobi-Bellman (HJB) equation, which regards the evolution of the value function $(v(a, z, t))$ implied by the optimization process, and by a forward-looking one, the Kolmogorov Forward equation (KFE), which describes the evolution of the distribution of agents over the wealth and productivity spaces. Denote $\partial_{x}$ and $\partial_{x x}$ the first and second partial derivatives with respect to $x$. Whenever the productivity is generated by a diffusion process, such as in equation (3-3), (5) show that this pair of equations is given by

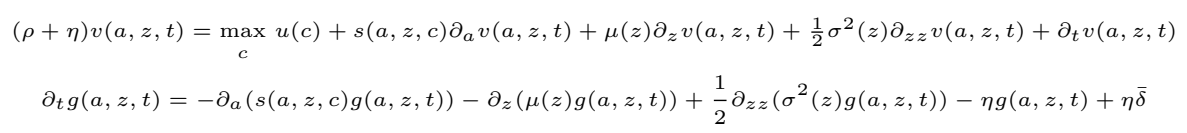

in which, through Itô's Lemma, $\mu(z)=\left(-\theta \log (z)+\frac{\sigma^{2}}{2}\right) z$ and $\sigma^{2}(z)=\sigma^{2} z^{2} \cdot \bar{\delta}$ is the distribution of agents who are born at every instant, compensating the fraction $\eta$ of agents that die. I assume that newborn individuals pop-up at the zero-wealth mark and with mean productivity.

\section{1}

\section{Wealth-Linear Restriction}

The exercise to be contemplated here is a fall in the parameter $\lambda$, from 3.2 (the 2006's American external finance to GDP ratio) to 2.6 (its 2010's analogue). Figure (5.1) plot the evolution of the aggregate capital in the economy as well as the implied interest rate path that balances the capital market along the transition. Since the joint distribution of wealth and productivity evolves smoothly, due to the continuous time approach, one should not expect that the aggregate supply would immediately adjust to a 
credit crunch shock. This short term supply-side insensitivity induces a large decrease in the interest rates, so as to motivate the active entrepreneurs to keep their capital demand unchanged in a more stringent credit market's setting. As time passes, capital begins to fall until it converges to a new steady-state level below the initial one (100 basis points smaller). It is worthwhile to stress that in the transition dynamics following the (5) methodology, both the initial and final level of capital are identical to the ones calculated in the steady-state equilibrium, since the forward-looking aspect of the KFE and the backwardlooking feature of the HJB ties the distribution of wealth and productivity in the end points of the time span.
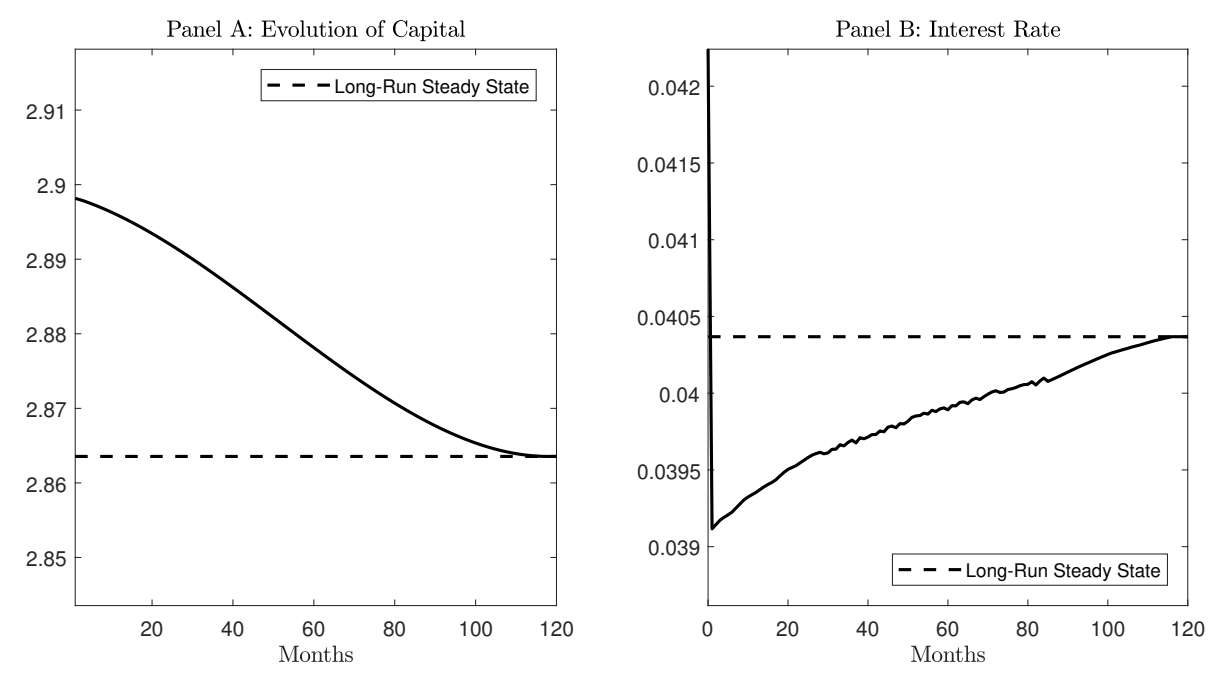

Figure 5.1: Capital and Interest Rate

In the steady-state analysis previously carried out, wealth inequality was predicted to rise in a more stringent credit market (i.e. $\lambda=2.6$ ). Figure (5.2) plots the evolution of the Gini Coefficient of Wealth after an unanticipated credit crunch shock. It increases rather rapidly in the beginning until it reaches an inflexion point and slowly converges to the final steady-state at 0.83 . In Panel (B) is also plotted the wealth distribution of entrepreneurs in three different points in time, along the transition: 1 month after the shock takes place; 5 years after it; and 10 years later, when it is already stabilized. It was shown that for the workers, apart from the zero-wealth mark, no substantial changes happen in their wealth distribution. Therefore, I omit its evolution from this section. 

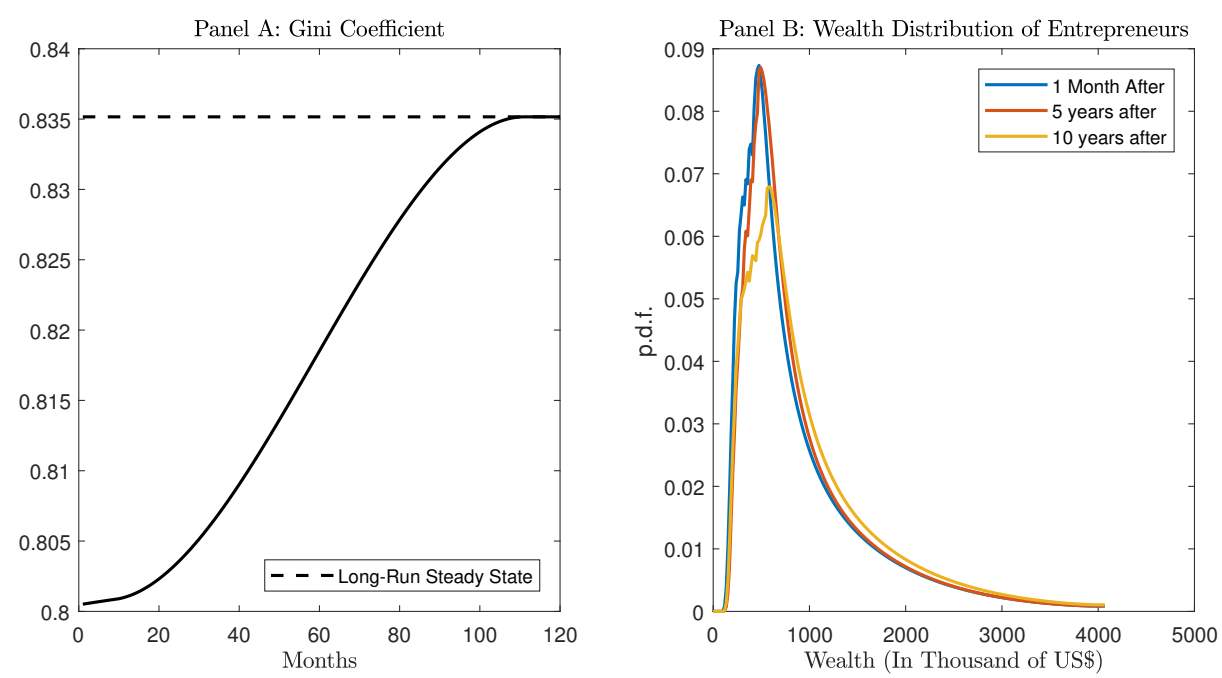

Figure 5.2: Gini Coefficient and Wealth Distribution

In order to check the importance of wealth accumulation for the aggregate welfare, measured by the aggregate consumption, I propose the following decomposition:

$$
\begin{gathered}
C^{o}(t)=E[c(a, z, t)]=\int_{a} \int_{z} c(a, z, t) g(a, z, t) d z d a, \\
C^{g}(t)=\int_{a} \int_{z} c(a, z, 0) g(a, z, t) d z d a, \\
C^{g^{-}}(t)=\int_{a} \int_{z} c(a, z, t) g(a, z, 0) d z d a, \quad \forall t .
\end{gathered}
$$

$C^{o}(t)$ is the aggregate consumption at time $t$. The first decomposition, $C^{g}(t)$, aims to capture the partial effect of the time variation of the joint distribution of wealth and productivity, $g(a, z, t)$, on the aggregate welfare. In this specification, $c(a, z, t)$ is kept fixed at its initial (pre-crisis) value. The second decomposition frames the effects on the economy's welfare that were not perpetuated by changes in $g(a, z, t)$. In this case, the distribution is held constant, and I let only $c(a, z, t)$ vary as time passes. Figure (5.3) plots the path of the aggregate consumption, as well as its proposed decomposition. Individuals' welfare declines along the transition, although the percentage change from the final steady-state to the initial one is almost unnoticeable $(0.3 \%)$.

Through the decomposition of the aggregate consumption, it is possible to conclude that shifts in the joint distribution of wealth and productivity would account, ceteris paribus, for an increase in overall welfare of $0.2 \%$. The fall in aggregate consumption was determined by other factors uncorrelated to chenges in $g(a, z)$ over time. 


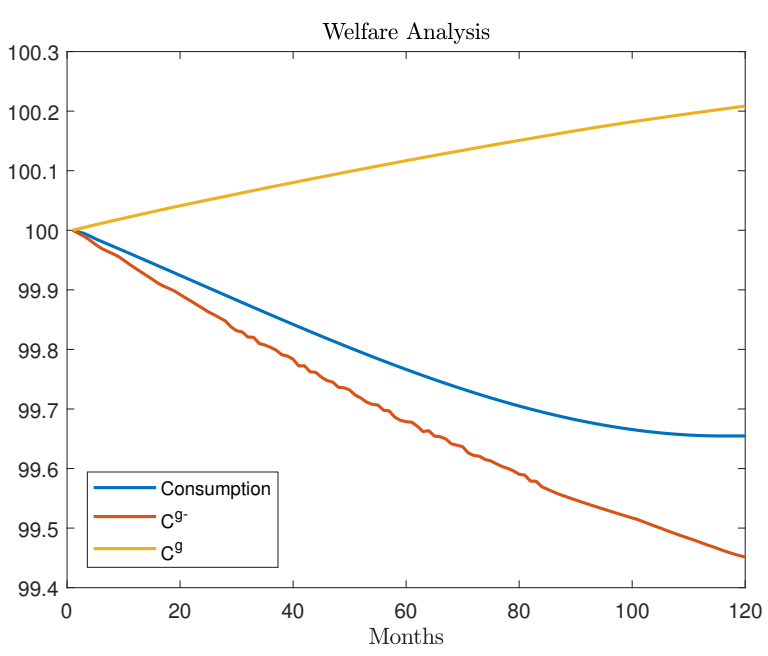

Figure 5.3: Welfare Decomposition

\section{2}

\section{The BKS Restriction}

In this section, I analyze the transition dynamics implied by an once-andfor-all credit crunch shock that permanently changes the parameter $\lambda$ from 0.69 to 0.63 .

As it was mentioned in the steady-state analysis, the BKS restriction predicts a larger impact on the intensive margin of the entrepreneurial activity, compared to the wealth-linear restriction. Aggregate capital decreases in 646 basis points. As it was mentioned, interest rates in the beginning of the transition are sharply reduced in order to maintain the same capital level of the pre-crisis calibrated economy. Transition to the new steady-state is longlasting, taking more than 8 years for the economy to stabilize in the new normal, as Figure (5.4) displays.
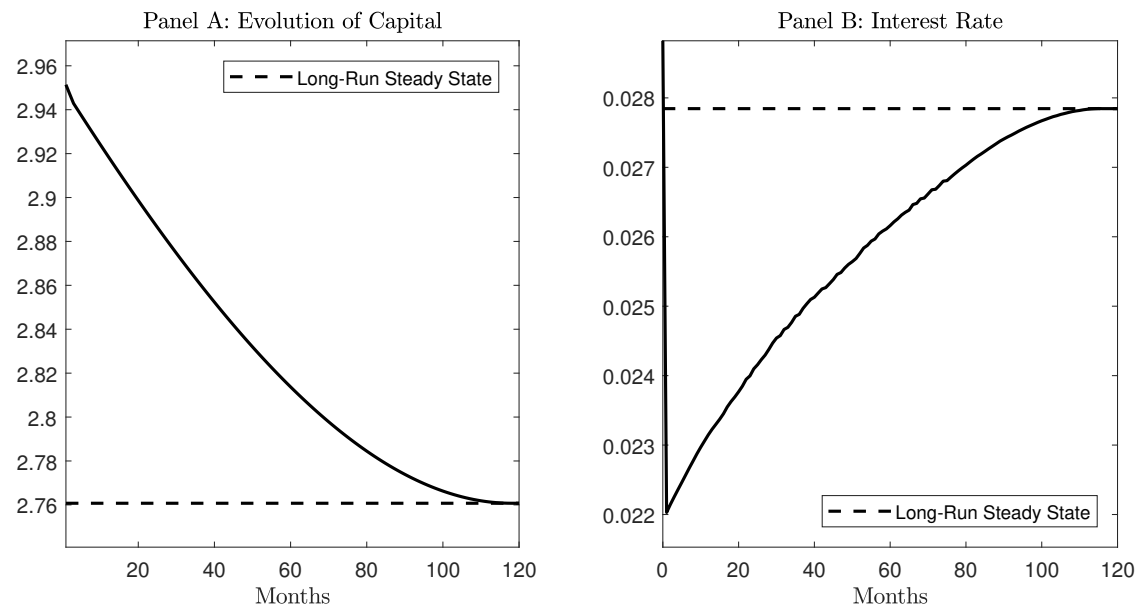

Figure 5.4: Capital and Interest Rate 
As it was observed in the wealth-linear restriction, here the model also predicts an increase in wealth inequality, although it is way stronger in the BKS setting, as it can be seen in Panel (A) of Figure (5.5). In Panel (B) it is depicted the wealth distribution of entrepreneurs in three points in the time span, until convergence to the final steady-state, 10 years after the credit crunch took place. It is possible to see that the right tail of the distribution becomes fatter over time.
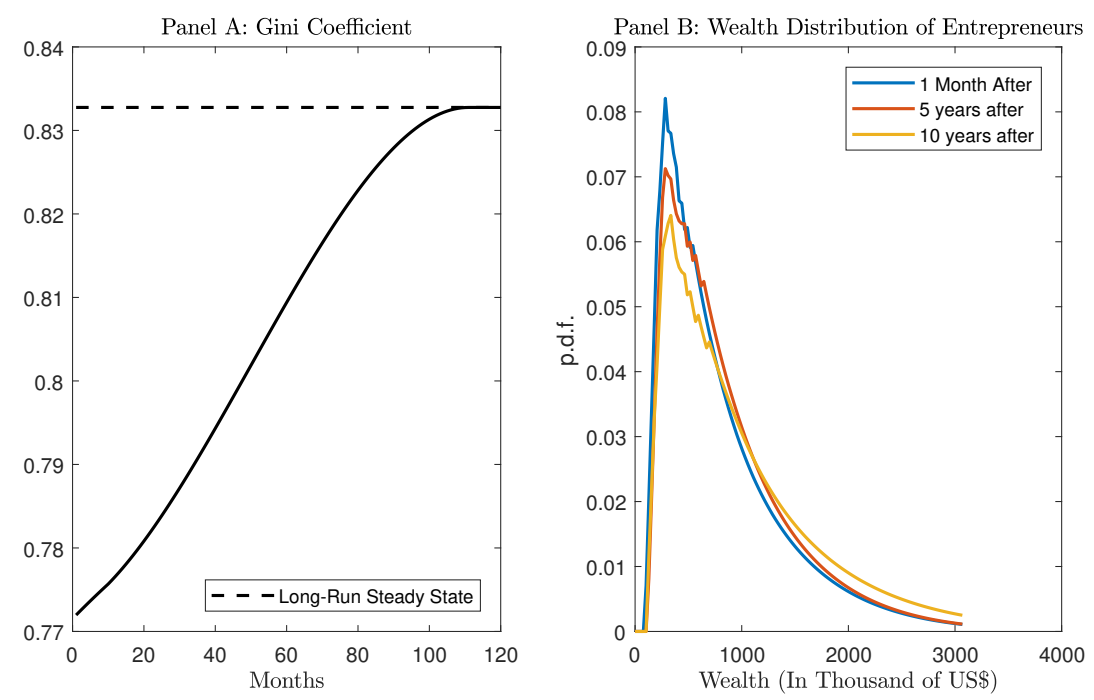

Figure 5.5: Gini Coefficient and Wealth Distribution

In order to quantify the effect of changes in the joint distribution of wealth and productivity to the model economy welfare, Figure (5.6) plots the evolution of the overall economy welfare, measured by the optimal aggregate consumption, as well as its partial decomposition. The overall fall in welfare amounts to $10 \%$. The partial effect of changes in the $g(a, z, t)$ along the transition has an almost negligible effect of $0.89 \%$. Keeping the distribution fixed along the transition, the model predicts a fall in welfare of $9.11 \%$. 


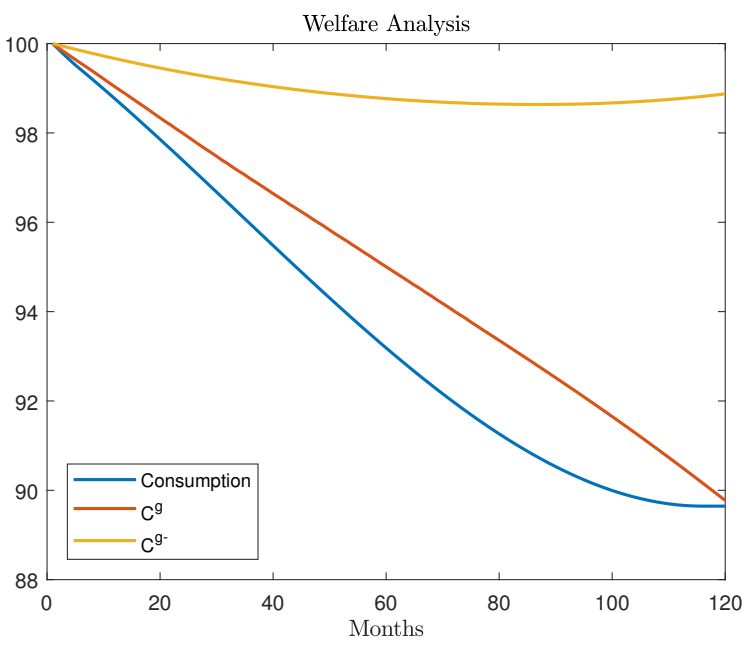

Figure 5.6: Welfare Analysis

Table (5.1) summarizes the percentage changes in some chosen variables caused by a tighter financial environment for both credit restriction specifications. Overall, the BKS constraint predicts stronger variations in the model economy, especially for the aggregate welfare.

\begin{tabular}{lcc} 
& Wealth-Linear & BKS \\
\cline { 2 - 3 } Share of Entrepreneurs & $-0.06 \%$ & $-0.55 \%$ \\
Share of Binded Entrepreneurs & $4.56 \%$ & $-0.21 \%$ \\
Capital Investments & $-1.19 \%$ & $-6.46 \%$ \\
Wealth Inequality & $4.33 \%$ & $7.87 \%$ \\
Workers Inequality & $5.84 \%$ & $8.13 \%$ \\
Entrepreneurs Inequality & $-4.24 \%$ & $1.07 \%$ \\
Welfare (Cummulative Losses) & $-0.3 \%$ & $-10 \%$
\end{tabular}

Table 5.1: Quantitative Comparison

Notes: This table compares the model predictions for changes in chosen outcomes between the pre-crisis and after-crisis $\lambda$. 


\section{6}

\section{Conclusions}

The main purpose of this work is to quantify how a financial deleveraging affects the wealth distribution of households when self-financing is a vital source of credit resources. In particular, it is investigated the implications of a credit crunch shock to the economy's wealth inequality along the transition to a new steady-state.

This dissertation leans on a model in which an imperfect capital market dampens the entrepreneurial activity of an economy populated by heterogeneous agents. Sources of heterogeneity are the agent's managerial talent to run a business and her accumulated wealth. The capital market imperfection stems from a limit on the amount of capital an active entrepreneur can employ in her production plant. I investigate the consequences of a credit crunch shock for two different capital restrictions specifications. The first one is a collateral constraint that solely depends on the agents wealth. The second one, based on (7), is endogenously determined by an enforcement problem faced by banks that want to guarantee that its debtors will fulfill with their credit obligations.

In a more stringent credit scenario, I showed that both binded and slack entrepreneurs accumulate more wealth in order to mitigate inefficiencies in their production decisions. The predicted shift in their wealth distribution is somewhat higher in the wealth-linear setting, which might explain why the credit crunch shock is less pervasive for both the extensive and intensive margins of the entrepreneurial activity. It is important to stress that since labor income is deterministic, the model may overestimate the increase in the economy's wealth inequality, since in the presence of a tougher credit environment, the fraction of workers with zero wealth increases substantially.

Finally, I showed that in the BKS restriction, welfare losses are noticeable vis-à-vis the wealth-linear restriction implications for the aggregate consumption. Through a decomposition of its evolution, I was able to quantify how much of its variation comes from changes in the joint distribution of wealth and productivity and how much stems from other sources. The former accounts for only $8.9 \%$ of the welfare losses. This finding may be very informative about the effectiveness of redistributive policies as a device to make agents better-off after a credit crunch takes place. 


\section{Bibliography}

[1] ALLUB, L.; EROSA, A.. Financial frictions, occupational choice and economic inequality. 2014.

[2] BASSETTO, M.; CAGETTI, M. ; DE NARDI, M.. Credit crunches and credit allocation in a model of entrepreneurship. Review of Economic Dynamics, 18(1):53-76, 2015.

[3] QUADRINI, V.. Entrepreneurship, saving, and social mobility. Review of Economic Dynamics, 3(1):1-40, 2000.

[4] CAGETTI, M.; DE NARDI, M.. Entrepreneurship, frictions, and wealth. Journal of political Economy, 114(5):835-870, 2006.

[5] ACHDOU, Y.; HAN, J.; LASRY, J.-M.; LIONS, P.-L. ; MOLL, B.. Income and wealth distribution in macroeconomics: A continuous-time approach. Technical report, National Bureau of Economic Research, 2017.

[6] BUERA, F. J.; SHIN, Y.. Self-insurance vs. self-financing: A welfare analysis of the persistence of shocks. Journal of Economic Theory, 146(3):845-862, 2011.

[7] BUERA, F. J.; KABOSKI, J. P. ; SHIN, Y.. Finance and development: A tale of two sectors. The American Economic Review, 101(5):1964-2002, 2011.

[8] EVANS, D. S.; JOVANOVIC, B.. An estimated model of entrepreneurial choice under liquidity constraints. Journal of political economy, 97(4):808-827, 1989.

[9] BUERA, F. J.; SHIN, Y.. Financial frictions and the persistence of history: A quantitative exploration. Journal of Political Economy, 121(2):221-272, 2013.

[10] MOLL, B.. Productivity losses from financial frictions: can selffinancing undo capital misallocation? The American Economic Review, 104(10):3186-3221, 2014. 
[11] QUADRINI, V.. Entrepreneurship in macroeconomics. Annals of Finance, 5(3-4):295-311, 2009. 


\section{A}

\section{Appendix}

In this appendix I show how one can assemble the HJB equation for the optimization problem as in 2-5.

The first step is to rewrite $2-1$ as follows:

$$
\begin{gathered}
v(a, z, 0)=E_{0} \int_{0}^{\infty} e^{-(\rho+\eta) t} u\left(c_{t}\right) d t \\
\Rightarrow v(a, z, 0)=u(c) d t+e^{-(\rho+\eta) d t} E_{0}[v(a, z, d t)]
\end{gathered}
$$

A first-order Taylor Expansion of $e^{-(\rho+\eta) d t}$ around $d t=0$ is $1-(\rho+\eta) d t$. Using this result and adding and subtracting $v(a, z, 0)$ in the RHS of A-1 yield

$$
(\rho+\eta) v(a, z, 0) d t=u(c) d t+E_{0}[d v(a, z)]
$$

where $E_{0}[d v(a, z)]=E[v(a, z, d t)-v(a, z, 0)]$. Finally, dividing both sides by $d t$, we finally have $2-5$. 